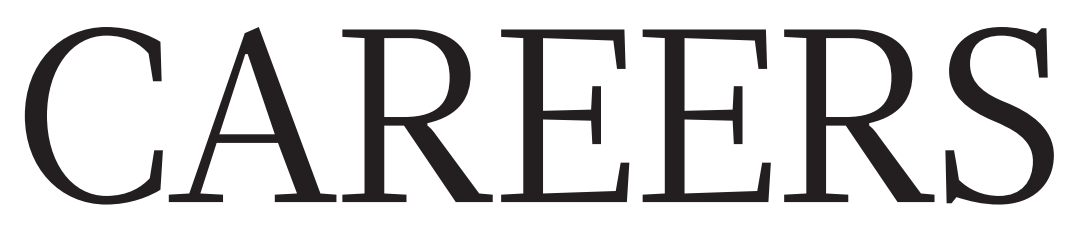

EDUCATION US needs to improve science literacy to prepare workforce $\mathbf{p} .130$
TURNING POINT Biochemist's high-risk research direction pays off $\mathbf{p . 1 3 1}$
NATUREJOBS For the latest career listings and advice www.naturejobs.com

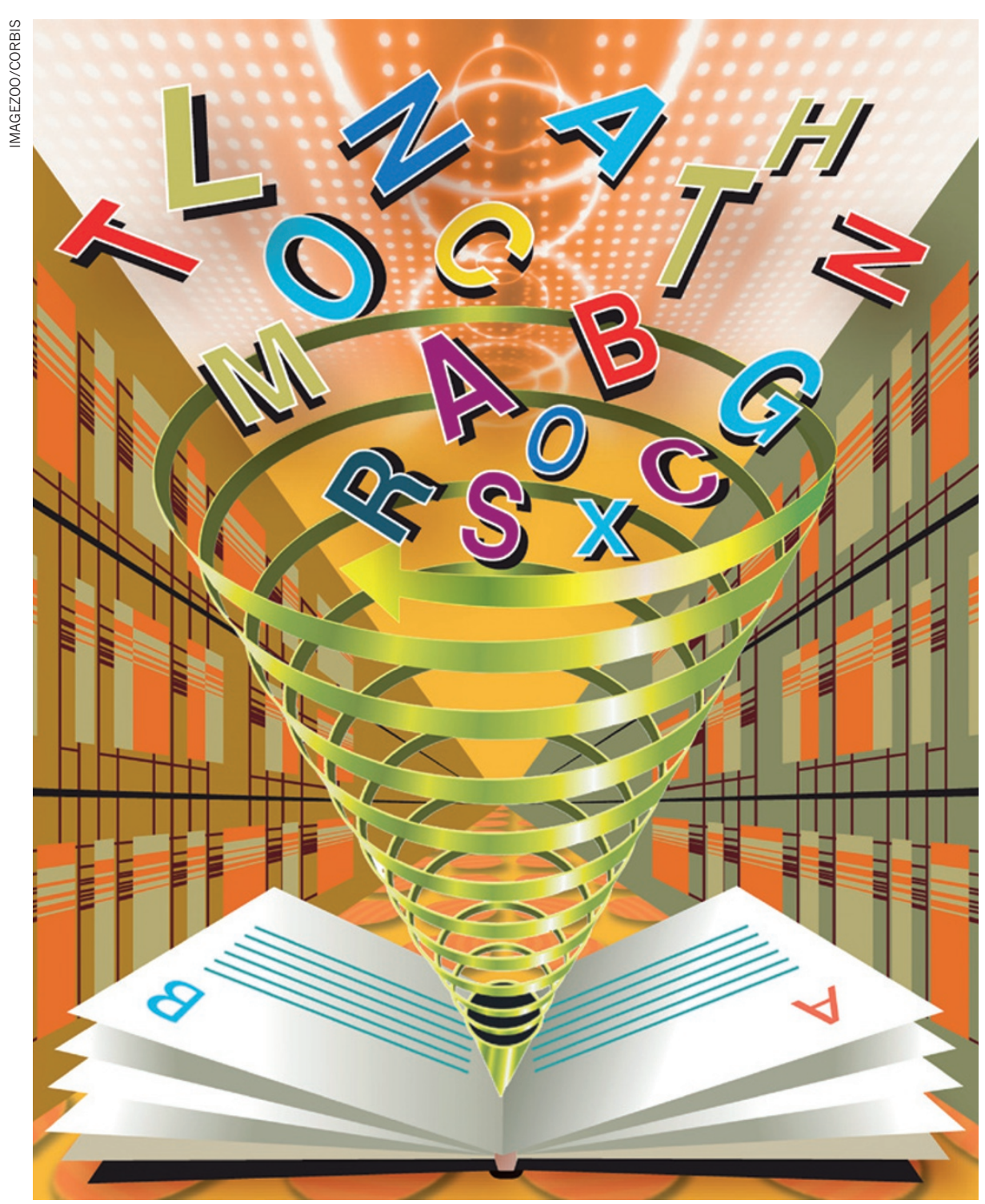

COLUMN
Turbocharge your writing today
Before you can tackle the overwhelming task of huge writing projects, you must first put aside some widely held myths, say Maria Gardiner and Hugh Kearns.
A $s$ a graduate student, you might find yourself well on the way with your education and 'ABD' (all but dissertation). Day after day, you tell yourself that you really, really intend to start writing your paper. After all, you've collected all the data, analysed them many times and entered them into tables.

But then you start thinking that maybe you need just a few more data. Perhaps, too, you should try a different analysis technique. And what if the tables you used aren't the right ones, or need to be formatted differently?

Many of the thousands of researchers we have worked with are constantly being tripped up by finicky, niggling details that keep them from writing up their research. Every day, they mean to start, but every day, something gets in their way or seems more importantand this can go on for years. Some very common obstacles get in the way of high-quality, high-quantity scholarly writing, but powerful, evidence-based techniques can help researchers to overcome repetitive and unhelpful habits and get moving (see 'How to get out of a dissertation-writing rut').

\section{WRITING MYTHS}

The biggest impediments to scholarly writing are long-held myths that seem to get passed down through the academic ranks like precious but unhelpful ancient wisdom. The first is the Readiness Myth - "I should write when I feel ready, and I don't feel ready yet". The secret to high output is that you have to write before you feel ready, because you might never reach that point. Researchers read endlessly and conduct countless experiments in the belief that it will eventually make them feel ready to write - we call these habits readitis and experimentitis. But ironically, all that reading and experimenting often makes them less likely to write, and more confused. So the first way to speed up your writing is to stop waiting, stop reading and experimenting, and start writing. You won't feel ready, but you have to do it anyway.

This brings us to the second myth, the Clarity Myth - "I should get it all clear in my head first, and then write it down". This isn't how writing works in practice. You have probably had the experience in which you were sure about how a paper would go until you started to write it. Then you discovered that there were inconsistencies, or it didn't flow well or the links didn't make sense. This tells you that it wasn't all that coherent in your head, after all. In fact, writing clarifies your thinking. Writing is not recording - you don't just take 


\section{EDUCATION}

\section{Better teaching needed}

The United States must boost the number of people pursuing degrees and careers in science, technology, engineering and maths (STEM), says a 23 June report from the National Academies. The nation should foster better education in schools, said the report, Successful K-12 STEM Education: Identifying Effective Approaches in Science, Technology, Engineering, and Mathematics. The authors also recommend improving STEM literacy to fill STEM-related jobs that do not require advanced degrees, such as science teacher or energy technician. The US Bureau of Labor Statistics says that only 4 of the 16 STEM-related jobs with the largest projected growth by 2018 need an advanced degree.

\section{JOB-HUNTING TOOLS}

\section{Inside information}

An online forum aims to give job seekers inside information about employers. CareerBliss (www.careerbliss.com/ company-questions) in Irvine, California, matches applicants with current employees who can answer queries. The forum has respondents for about 500 companies, universities and organizations in the United States including biopharmaceutical firms such as Pfizer and Genentech, says spokeswoman Alia Henson. Questions can be on any topic, including research funding or grant opportunities.

\section{FAMILIES}

\section{Women want flexibility}

Female early-career researchers with newborn babies are most likely to want to keep their jobs if their employers provide security and flexibility, including the right to leave work to care for an ill child, a study finds. Published on 23 May in the bi-monthly Journal of Applied Psychology (D. S. Carlson et al. J. Appl. Psychol. doi:10.1037/a0023964; 2011), the study reports better job retention for new mothers who stay physically and mentally healthy as a result of accommodations. Lead author Dawn Carlson, a professor of management at Baylor University in Waco, Texas, says that scientists should check how a prospective employer handles the needs of families before accepting an offer. To retain female staff, universities should allow maximum flexibility. "Whether extending the tenure clock or some other measure, the organization has to figure out a way to support these people if they want to reduce turnover," says Carlson.

a photocopy of what is in your head and put it on the page. It is a far more creative and interactive process. As you write, you develop your thoughts. Writing is, in fact, rigorous thinking. So the second way to turbocharge your writing and improve its quality is to get the words down on the page - no matter how bad you think they look or sound at first.

\section{SNACK WRITING}

Once researchers get beyond the myths that stop them writing, they often declare that they can't possibly write anything eloquent, insightful or clever unless they have a whole day or week to do it in. And because they don't have that amount of time, they conclude that there is no point in starting. We call this 'binge writing. Binge writing isn't inherently wrong; it's just that, for busy people, it can greatly reduce the amount of writing

\section{"Get the words down on the page - no matter how bad you think they look or sound at first."} they do. The alternative is 'snack writing'. This means short - but regular - writing sessions. We suggest about 1-2 hours a day for graduate students who are writing a dissertation, and about 45-90 minutes a day for researchers trying to increase their publication output.

Many researchers tell us that they couldn't possibly get anything useful written in that amount of time. The good news is that studies (which we have replicated many times in practice) show that academics who write for 30 minutes a day produce, on average, more peer-reviewed publications than academics who write for big blocks of time. But the 'snacks' have to be regular -45 minutes once a week doesn't work, but 45 minutes a day 5 days a week does wonders. When possible, try snack writing first thing in the morning. Our experience suggests that this increases the chances of success by minimizing distractions and ensuring that you have sufficient energy to write clever things. However, for snack writing to lead to really high-quality results, you also need to write in a very specific way.

\section{WHAT IS WRITING?}

Before we tell you what writing is, we should tell you what it isn't, at least for the purposes of snack writing.

Writing isn't editing: you should not spend your brief snack-writing time trying to find the perfect word or getting your grammar right. Writing isn't reading journal articles for research: write first and read afterwards, so that your writing shows you what you need to read. Writing isn't referencing: when you make that killer argument and want to reference Smith and Brown (2006; or maybe it was 2007?), don't stop and look it up. Write "Smith \& Brown (200??)" and keep going. You can look up the reference later. Furthermore, writing is not formatting, literature searching, photocopying, e-mailing or nosing around on Facebook. Writing - at least for your snack-writing sessions means putting new words on the page or substantially rewriting existing words.

So, you might ask, when do you do all the editing, reading and other associated tasks? The answer is, any time in the other 23 hours and 15 minutes of the day - just not during your snack-writing time.

So stop waiting to feel ready. Get started with some short and regular writing snacks. What you write won't be perfect at first, but you will be on your way to becoming a prolific academic writer.

Maria Gardiner and Hugh Kearns lecture and research in psychology at Flinders University in Adelaide, Australia, and run workshops for graduate students and advisers (see ithinkwell.com.au).

\section{TOP TIPS}

\section{How to get out of a dissertation-writing rut}

- Write before you feel ready - because you might never feel ready. It's amazing how people magically feel ready when there is an imminent deadline.

- Don't wait to have a clear picture of the paper. As you start putting down your ideas, you may actually clarify them. - Snack write - work in short, frequent bursts instead of waiting to sit down for big blocks of time. Those blocks hardly ever come, and when they do, they don't usually get used very productively. - Set specific times in your schedule for writing - don't leave it to chance, because chances are it won't happen. - Writing means putting new words on the page or substantially rewriting old words. It does not mean editing, reading, referencing or formatting - and it definitely does not mean composing e-mails. - If you refrain from writing because you worry that what you write won't be good enough, try noting the adage that to write well, you first have to write.

- To really increase the quality and quantity of your writing, get feedback from mentors and colleagues - it can be painful, but it works. M.G. and H.K. 